\title{
Comparing modern and Pleistocene ENSO-like influences in NW Argentina using nonlinear time series analysis methods
}

\author{
Norbert Marwan ${ }^{1}$, Martin H. Trauth ${ }^{2}$, Mathias Vuille ${ }^{3}$, Jürgen Kurths ${ }^{1}$ \\ 1 Nonlinear Dynamics Group, Institute of Physics, University of Potsdam, Potsdam 14415, Germany \\ 2 Institute of of Earth Sciences, University of Potsdam, Potsdam 14415, Germany \\ 3 Climate System Research Center, Department of Geosciences, University of Massachusetts, Amherst, USA
}

Received: date / Revised version: date

\begin{abstract}
Higher variability in rainfall and river discharge could be of major importance in landslide generation in the north-western Argentine Andes. Annual layered (varved) deposits of a landslide dammed lake in the Santa Maria Basin $\left(26^{\circ} \mathrm{S}, 66^{\circ} \mathrm{W}\right)$ with an age of $30,000{ }^{14} \mathrm{C}$ years provide an archive of precipitation variability during this time. The comparison of these data with present-day rainfall observations tests the hypothesis that increased rainfall variability played a major role in landslide generation. A potential cause of such variability is the El Niño/Southern Oscillation (ENSO). The causal link between ENSO and local rainfall is quantified by using a new method of nonlinear data analysis, the quantitative analysis of cross recurrence plots (CRP). This method seeks similarities in the dynamics of two different processes, such as an ocean-atmosphere oscillation and local rainfall. Our analysis reveals significant similarities in the statistics of both modern and palaeo-precipitation data. The similarities in the data suggest that an ENSO-like influence on local rainfall was present at around $30,000{ }^{14} \mathrm{C}$ years ago. Increased rainfall, which was inferred from a lake balance modeling in a previous study, together with ENSO-like cyclicities could help to explain the clustering of landslides at around 30,000 ${ }^{14} \mathrm{C}$ years ago.
\end{abstract}

\section{Introduction}

Climate is a major influential factor for mass movements in high mountain regions. Increased humidity (Dethier and Reneau 1996) or increased variability in rainfall (Grosiean et al. 1997; Keefer et al.1998) can reduce thresholds for catastrophic landsliding. In order to estimate the influence of climate in a given region, the climatic conditions during episodes with enhanced landsliding are compared with periods without important mass movements. The precise definition of climate scenarios at

Correspondence to: Norbert Marwan

e-mail: marwan@agnld.uni-potsdam. de times of high rock avalanche activity helps us to define threshold values for increased landsliding.

About $30,000{ }^{14} \mathrm{C}$ years ago, multiple large rock avalanches with volumes in excess of $10^{6} \mathrm{~m}^{3}$ occurred in the arid to semiarid intra-andean basins of north-western Argentina (Strecker and Marret 1999; Hermanns and Strecker 1999; Trauth and Strecker 1999). A potential mechanism that could have caused this enhanced landsliding in such an environment is climate change. Increased humidity and/or higher interand intraannual rainfall variability results in higher river discharge and erosion in narrow valleys and therefore increased destabilization of mountain fronts.

The climatic conditions in NW Argentina are not well known for the period at around $30,000{ }^{14} \mathrm{C}$ years ago. Marine and terrestrial records from tropical and subtropical South America indeed suggest more humid conditions (the Minchin period between 40,000 and $25,000{ }^{14} \mathrm{C}$ years ago, e. g. van der Hammen and $\mathrm{A}$ 1994; Ledru et al. 1996; Godfrev et al. 1997; Turca et al. 1997) and a strong El Niño/ Southern Oscillation (ENSO) (e. g. Oberhänsli et al. 1990; Beaufort et al. 2001). Various modeling studies have shown an impact of orbital forcing on ENSO and its weakening during the ice ages (Clement et al. 1999; Liu et al. 2000). Thus El Niño events may be rare around $30,000{ }^{14} \mathrm{C}$ years ago (Clement et al. 1999). Beaufort et al. (2001), however, inferred from Coccolithophores production a significant occurence of the ENSO for this period, and Tudhope et al. (2001) based on the analysis of annually banded corals concluded that ENSO has been a persistent component of the climate system over the past $130 \mathrm{ka}$.

However, the local signal of the climatic changes in NW Argentina is still not well defined. Laminated sediments from a former landslide dammed lake in the Santa Maria Basin (NW Argentina, $26^{\circ} \mathrm{S} 66^{\circ} \mathrm{W}$ ) contain valuable information about the environmental conditions for the period around 30,000 ${ }^{14} \mathrm{C}$ years ago (Trauth and Strecker 1999; Trauth et al. 2000). Hydrologic modeling of this palaeo-lake indeed indicates significantly wetter conditions during this time compared to the present (around 10 to $15 \%$ higher precipitation, Bookhagen et al. 2001). Linear spectral analysis of palaeoprecipitation data derived from annual layered (varved) lake 
sediments also suggest an ENSO-like influence on rainfall and consequently increased interannual rainfall variability in river discharge and erosion (Trauth and Strecker 1999; Trauth et al. 2000). However, the results of such linear methods are often ambiguous and not appropriate, since natural processes are complex, exhibit nonstationarities and are mostly recorded as short and noisy time series. In fact, data gained from sedimentation processes (as colour data) are nonstationary by their origin and the relationship between climatic forcing and rainfall is not expected to be linear. Linear methods are usually unsuitable to investigate natural complex data. In addition, these approaches do not provide any information about a change in the climate dynamics, e. g. the sign of precipitation changes related to ENSO-like oscillations.

The aim of our work is to test the hypothesis that an enhanced ENSO-like influence on local rainfall caused a temporal landslide cluster $30,000{ }^{14} \mathrm{C}$ years ago. For this purpose, we first try to identify ENSO-like patterns in present-day precipitation data and infer causal links between this ocean-atmosphere oscillation and local rainfall. Secondly, we search for similar influences in palaeo-precipitation data reconstructed from $30,000{ }^{14} \mathrm{C}$ year old lake sediments. This comparison is carried out using a new method of nonlinear data analysis, the cross recurrence plots (CRP), which can be applied to short and nonstationary complex data (Marwan and Kurths 2002). This procedure traces similarities and differences in several measures of complexity in both modern and past rainfall data. Significant occurrences of the ENSO-rainfall teleconnection together with increased rainfall could help to explain enhanced landsliding $30,000{ }^{14} \mathrm{C}$ years ago in NW Argentina where no major mass movements occur today.

\section{Present-day Climatic Conditions}

Summertime climate and atmospheric circulation over NW Argentina is largely governed by the South American monsoon system (e. g. Zhou and Lau 1998), featuring heavy precipitation, an upper-air anticyclone (Bolivian High) and a lowlevel trough (Chaco low). Approximately $80 \%$ of the annual precipitation amount falls within the summer months November-February (Bianchi and Yañez 1992), associated with southward moisture transport to the east of the Andes through the Andean low-level jet (e.g. Nogués-Paegele and Mo 1997). The intra-andean basins and valleys, separated from this low-level moisture flux through the north-south running eastern Andean ridge, are arid and receive less than $200 \mathrm{~mm} \mathrm{yr}^{-1}$, whereas the regions to the east of this orographic barrier receive more than $1500 \mathrm{~mm} \mathrm{yr}^{-1}$ (Bianchi and Yañez 1992).

Due to the seasonal change in the tropospheric temperature gradient between low and mid-latitudes, the subtropical westerly jet extends further north during the winter months, reaching its northernmost position around $27^{\circ} \mathrm{S}$. The resulting wintertime mean westerly flow, which prevails over the study region in the mid- and upper troposphere, hinders regional moisture transport over the eastern slopes of the Andes and leads to a typically dry winter climate (less than $50 \mathrm{~mm}$ per month).

On interannual time scales, summer precipitation in the Central Andes, is primarily related to changes in meridional baroclinicity between tropical and subtropical latitudes, which in turn is a response to sea surface temperature anomalies in the tropical Pacific (e. g. Vuille et al. 2000; Garreaud and Aceituno 2001; Garreaud et al. in press). The study region therefore shows a significant relationship with ENSO, featuring a weakened westerly flow with a significantly enhanced easterly moisture transport during La Niña summers and strengthened westerly flow with a significantly subdued easterly moisture transport during El Niño summers. As a result, the rainy season is much more active during La Niña episodes and less active during El Niño episodes. These ENSO related atmospheric circulation anomalies are also evident in radiosonde data to the east of the Central Andes over NW Argentina (Salta), featuring enhanced southeasterly (northwesterly) flow and increased (decreased) specific humidity levels in the lower and mid-troposphere during La Niña (El Niño) summers (Vuille 1999). The notion that this ENSO influence indeed extends beyond just the Central Andes is further supported by several recent studies, which indicate that precipitation anomalies in this part of the Andes tend to coincide with anomalies of the same sign over SE Bolivia and NW Argentina (e.g. Aceituno and Montecinos 1997; Garreaud 1999). Bianchi and Yañez (1992) also report a weak but significant tendency toward less rain during El Niño years, based on a high-density network of 380 weather stations. Trauth et al. (2000) provide a detailed statistical analysis on the same data set showing that this tendency is very obvious but spatially and temporally highly variable. As indicated in Figure 1for the representative El Niño event 1965/66, precipitation can be decreased up to $80 \%$ with respect to the long-term average in rainfall, with a more significant reduction in the northern part of the study area. A composite analysis of the monthly summer precipitation (DJFM) difference between El Niño and La Niña summers between 1979 and 1999 based on CMAP satellite-derived precipitation data (Xie and Arkin 1997) confirms this notion (Fig. 2). Although weak, the tendency toward less precipitation during El Niño and more precipitation during La Niña episodes is evident even in this low-resolution gridded data. Similar to the pattern in Figure 1 the ENSO signal is reversed a few degrees further south, where summer precipitation becomes less dominant.

\section{3-Methods}

It is difficult to compare rainfall proxies from $30,000{ }^{14} \mathrm{C}$ year old lake sediments with present precipitation data. The process recording weather and climate in palaeo-archives is complex and so far not very well understood (Saltzman 1990; Bradley 1999). Because of various signal distortions in both time and frequency domain, the use of linear data analysis methods reaches its limits. The complexity of natural processes suggests the application of nonlinear methods instead 


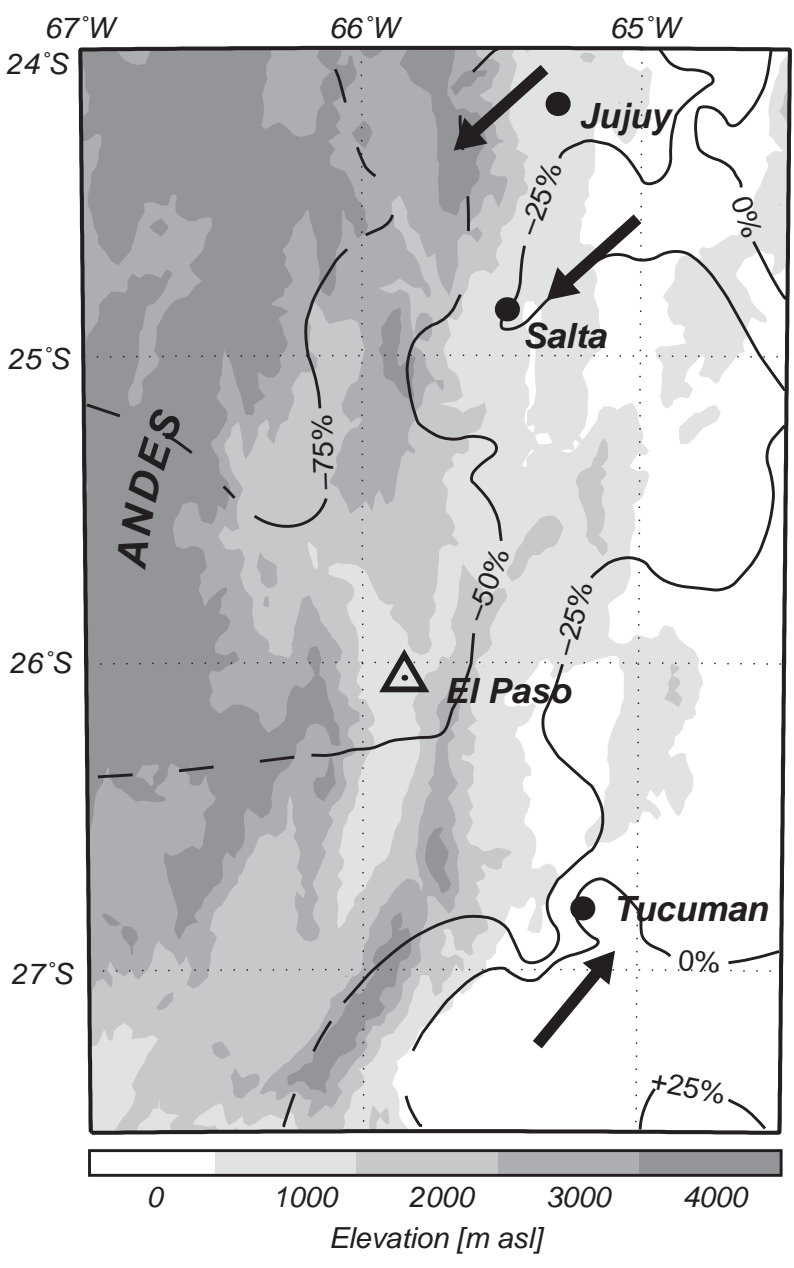

Fig. 1 Study area in the Santa Maria Basin with the locality of annual layered lake deposits in the locality El Paso, the relative precipitation anomaly during the El Niño 1965/66 compared to mean annual precipitation (annual precipitation as a mean from July to June; data from Bianchi and Yañez 1992) and the prevailing wind directions during January (black arrows; wind directions from Prohaska 1976).

for the analysis and comparison of such complex processes. Most of the nonlinear standard techniques, such as fractal dimensions or Lyapunov exponents, cannot be estimated for such data (Kantz and Schreiber 1997). Therefore, we have tried to quantify cross recurrence plots of present-day and palaeo-data. This reveals a suite of complexity measurements which give hints to identify similar patterns in present-day and palaeo-data. This comparison first tests the hypothesis that the signal extracted from the lake sediments is an appropriate measure for palaeo-precipitation. Secondly, it helps to reconstruct the variability in annual rainfall as compared to the present. Both results can then be used to test the hypothesis that increased interannual variability in climate can explain enhanced landslide activity $30,000{ }^{14} \mathrm{C}$ years ago.

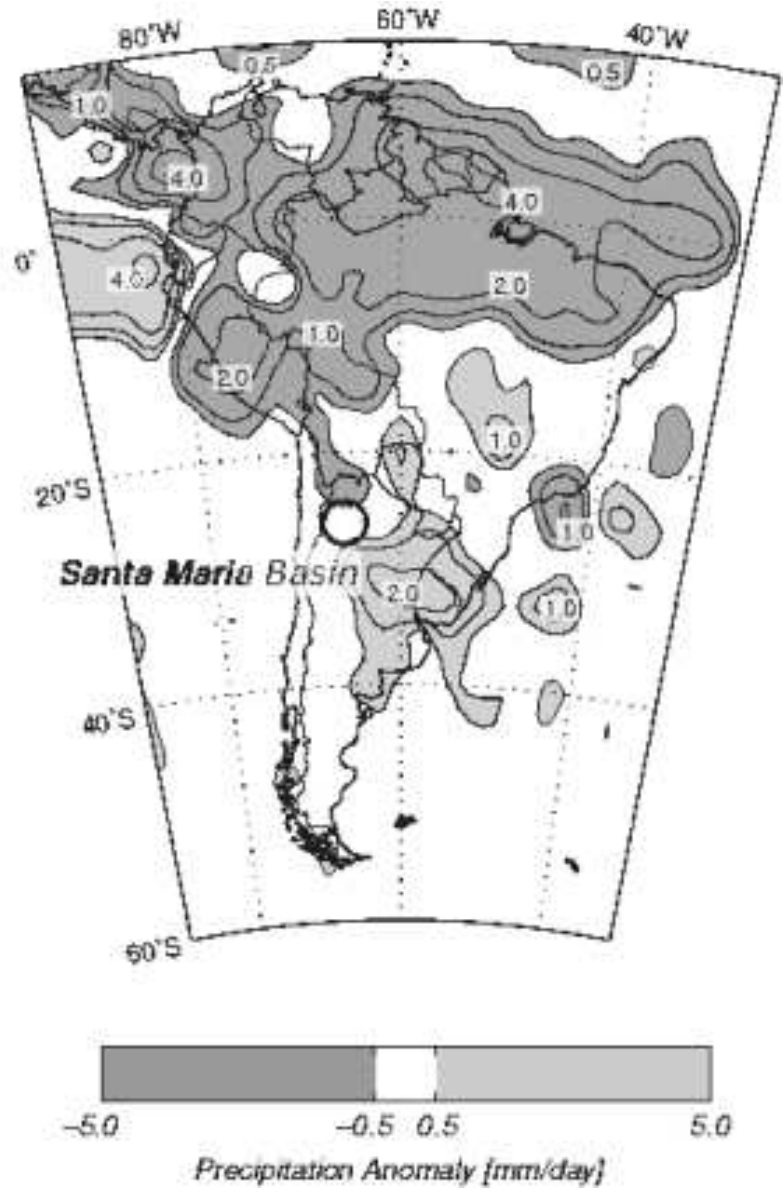

Fig. 2 Difference in precipitation (in $\mathrm{mm} \mathrm{day}^{-1}$ ) between El Niño and La Niña periods (El Niño - La Niña) for December - March based on CPC merged analysis of precipitation (CMAP, Xie and Arkin 1997) between 1979 and 1999. Contour interval is $-4,-2,-1,-0.5,0.5,1,2,4 \mathrm{~mm} \mathrm{day}^{-1}$, regions with difference $>0.5(<-0.5)$ shaded in light (dark) gray. An El Niño (La Niña) event is defined as a phase of at least six consecutive months in which the 5-month running mean of SSTA in the NINO3.4 region exceeds (or remains below) $0.5^{\circ} \mathrm{C}\left(-0.5^{\circ} \mathrm{C}\right)$. The reference period for the SSTA is 1961-90.

\subsection{Cross recurrence plots $(C R P)$}

An important aspect of climate changes involves nonlinear interactions among many components of the earth's environmental system (e. g. Palmer 1999). These components include the oceans, land, lakes and continental ice sheets, and involve physical, biological, and chemical processes. Many of the techniques used to diagnose climatic variability such as Fourier analysis, empirical orthogonal functions or singular value decomposition are formulated using methods taken from linear analysis. However, while using these techniques it is difficult to analyze the nonlinear character of the earth's climate system. In the last two decades, a great variety of nonlinear techniques have been developed to analyse data of complex processes. Most popular are methods to estimate fractal dimensions or Lyapunov exponents (e. g. Mandelbrot 1982; Wolf et al. 1985; Kurths and Herzel 1987; Kantz and Schreiber 
1997). However, a number of pitfalls are possible due to the uncritical use of these methods on natural data, which are typically nonstationary and noisy. Furthermore, we cannot expect low dimensions in highly complex natural processes. Therefore, we have modified and applied the nonlinear data analysis method of cross recurrence plots, which was recently introduced by the extension of recurrence plots (Zbilut et al. 1998: Marwan et al. 2002), for detecting similarities and differences in the ENSO influence in present-day and past rainfall data. In order to quantify such similarities by using CRPs, new measures of complexity were introduced. Measures of complexity were developed in order to quantify the complexity of processes; the simplest measure is the entropy, which distinguishs between noisy and periodically processes. Here we use an approach which uses the geometrical structures which are contained in CRPs. This new technique is particularly efficient for the analysis of rather nonstationary, short and noisy data and was successfully applied to prototypical model systems with nonlinear interrelations (Marwan and Kurths 2002). Thus, the CRP is an appropriate method for time series analysis of climate and palaeo-climate data.

The basic idea of this approach is to compare the dynamics of two processes which are both recorded in a single time series. Following Taken's embedding theorem (Takens 1981), the dynamics of a process with $\hat{m}$ state parameters (i.e. $\hat{m}$ differential equations), which is, however, measured by only one time series $u(t)=u_{i}$ with length $N$ and a sampling time $\Delta t$ (i.e. $t=i \Delta t$ ), can be appropriately presented in its reconstructed phase space of a dimension $m$ (theoretically when $m>2 \hat{m}+1)$. Such a reconstruction can be formed by using the time delay method (embedding), where for each component of the state vector a value of the time series after a predefined delay $\tau$ (time delay) is choosen:

$$
\mathbf{x}_{i}=\left(u_{i}, u_{i+\tau}, \ldots, u_{i+(m-1) \tau}\right), i=1 \ldots N,
$$

The dimension $m$ of such a reconstructed state or phase space is called embedding dimension. The time evolution of the state vectors forms a trajectory $\mathbf{x}_{i}$, which runs through all possible states at time $t=i \Delta t$ and, thus, present the dynamics of the process.

The similarity in the behaviour of both processes in this reconstructed phase space can be examined by using the CRP, which visualizes the distance between segments of their phase space trajectories $\mathbf{x}_{i}$ and $\mathbf{y}_{i}$ of the embedded time series (Marwan 2002)

$$
\mathbf{C R}_{i, j}^{+}=\Theta\left(\varepsilon-\left\|\mathbf{x}_{i}-\mathbf{y}_{j}\right\|\right), \quad i, j=1 \ldots N,
$$

where $\varepsilon$ is a predefined cut-off distance, $\|\cdot\|$ is the norm (e. g. the Euclidean norm) and $\Theta(x)$ is the Heaviside function. Depending on the type of the application, $\varepsilon$ can have a fixed value or can vary for each $i$ in such a way that a predefined number of neighbours occur within a certain radius $\varepsilon$ (Eckmann et al. 1987; Marwan et al. 2002). This results in a constant density of recurrence points in each column of the $\mathrm{CRP}$ and is particularly useful in the analysis of complex processes with differences in the variability of the amplitudes.
The CRP is a two-dimensional $N \times N$ array of points where $N$ is the number of embedding vectors obtained from the delay coordinates of the input signal. The values of the CRP are one (black points) if trajectories lie close to each other (recurrence points), whereas values of zero (white points) document rather large distances between two trajectories. From the occurrence of lines in the CRP parallel to the diagonal in the recurrence plot it can be seen how fast neighbouring trajectories diverge in the phase space. Recurrent data in a system would create diagonal lines in a distance $t$ from the main diagonal in such a plot comparing both phase-space embeddings with respect to the time delay $t$. It is important to note that an additional CRP with opposite signed second time series $\mathbf{C} \mathbf{R}_{i, j}^{-}=\Theta\left(\varepsilon-\left\|\mathbf{x}_{i}+\mathbf{y}_{j}\right\|\right)$ allows to distinguish positive and negative relations.

Visual inspection of CRPs already reveals valuable information about the relationship between two complex processes. However, a better understanding of causal links between both processes demands a more quantitative examination of the CRPs. Therefore, we introduce the following two statistical measures of complexity (Marwan and Kurths 2002):

the recurrence rate,

$$
R R(t)=\frac{1}{N-i} \sum_{j=1}^{N-i}\left(\mathbf{C R}_{j, j+i}^{+}-\mathbf{C R}_{j, j+i}^{-}\right)
$$

and the averaged diagonal length

$$
L(t)=\frac{\sum_{l=l_{\min }}^{N-i} l\left[P^{+}(l, t)-P^{-}(l, t)\right]}{\sum_{l=l_{\min }}^{N-i}\left[P^{+}(l, t)-P^{-}(l, t)\right]},
$$

where $l_{\min }$ is a predefined minimal length of a diagonal line segment, $P^{ \pm}(l, t)$ is the histogram of the diagonal line lengths in $\mathbf{C} \mathbf{R}^{ \pm}$at a distance $t$ from the main diagonal (i.e. the time delay $t$ between the two phase space vectors) and $t=i \Delta t$. The $R R(t)$ is the density of adjacent states, i. e. of the recurrence points in a CRP diagonal. $R R(t)$ therefore measures the probability of similar states in both processes after a delay time $t$. High densities of recurrence points in a diagonal cause high values of $R R$, which is typical for processes with a similar behaviour in the phase space.

Strongly fluctuating data cause short or absent diagonals in the CRP, whereas data from deterministic processes produce longer diagonals. If two deterministic processes have the andineurths imilar phase-space behaviour, i. e. the phase-space trajectory reaches the same regions of the phase space during certain times, then the number of longer diagonals will increase and the amount of short diagonals decrease. The average diagonal length $L$ measures the epoch length (i.e. the time span) of significant similarities in the behaviour of both processes. The higher the coincidence of both processes, the larger the length of these diagonals.

Consequently, high values of $R R$ and $L$ correspond to frequent and longer periods of similar behaviour of the processes as recorded in the time series data. Therefore, these parameters are appropriate quantitative measures for the similarities between both processes. However, extrema at longer 
delays $t$ do not necessarily correspond with high correlations. Future work will concentrate on the theoretical and more detailed investigation of the interrelations between the structures in CRPs.

We have proposed a statistical evaluation of the quantitative measures of the CRP with an ensemble of a large amount of surrogate data.

The assumption for the surrogate data is that the considered processes are linearly independent and do not have any similar dynamics. These surrogates should reveal some features like in our original data but also features caused by the randomness of a possible correlation (stochastic processes). Linear correlated noise is a paradigmatic example for such processes (Kantz and Schreiber 1997). We calculate a surrogate time series based on this class of processes with the following recursive function, a autoregressive process of order $p$,

$$
x_{n}=\sum_{i=1}^{p} a_{p} x_{n-p}+b \xi_{n},
$$

where $\xi$ is white noise and $a_{i}$ are coefficients which determine the auto-correlation of the system and allow to adapt this stochastic system to our natural processes. We fit the model to the precipitation series of the station Tucuman. Then we perform the CRP analysis using the SOI data and the ensemble of, e.g. 10,000 realizations of precipitation series produced by the AR model. Using the distributions of the $R R$ and $L$ measures we can estimate their empirical confidence bounds (we will use the $2 \sigma$-bounds which approximately correspond with the $95 \%$ confidence level).

With these confidence bounds we can evaluate the obtained measures of CRP and the relations of the natural processes. Since the surrogates are from a stationary system and the natural data are nonstationary, we have further applied this kind of evaluation to more stationary segments in the natural data. We got the same results. This kind of surrogates is a special realization, which is prototypical for linear stochastic processes, and there are a lot of other possibilities to construct surrogates.

\subsection{Comparison of modern and palaeo-precipitation variability}

In order to test the new method on precipitation data, we first compute the CRP for rainfall stations with well established and clear ENSO influence. We use monthly precipitation data from the cities of Buenos Aires (BAI) and Caracas (CAR) from the WMO data set (Hoffmann 1975). For the assessment of the modern ENSO influence on local rainfall in NW Argentina, we analyze monthly precipitation data from three stations: San Salvador de Jujuy (JUY), Salta (SAL) and San Miguel de Tucuman (TUC; Figs. 1 and 3B). These stations in the capitals of the provinces Jujuy, Salta and Tucuman provide the longest time series from this area and are located on a north-south transect. Moreover, these locations are influenced by different local winds; Jujuy and Salta mainly receive north-easterly and easterly moisture-bearing winds during the summer rainy season, whereas Tucuman is characterized by southerly and south-westerly winds (Prohaska 1976). The Southern Oscillation Index (SOI) is used as a measure for the ENSO variability between the years 1884 and 1990 (Fig. 3A, based on COADS data). This index is the normalized difference between the sea level air pressure in Tahiti and Darwin. Extreme negative values represent El Niño events and extreme positive values represent La Niña events (Ropelewski and Halpert 1987). In our analysis, we use monthly data, i.e. twelve data points per year in order to avoid loosing valuable intraannual information. Moreover, longer data vectors improve the significance of the CRP measures, thus the use of annual data would significantly reduce the value of our results. The potential distortion of the final result by differences in the causal linkage between ENSO and rainfall over the year, i. e. between dry and wet season, is believed to be of minor importance since the absolute values of precipitation during the dry season are low and hence the contribution to the analysis is small. The rainfall variability during the dry season is not significantly different from white noise and disappears after low-pass filtering preceding the actual time series analysis.
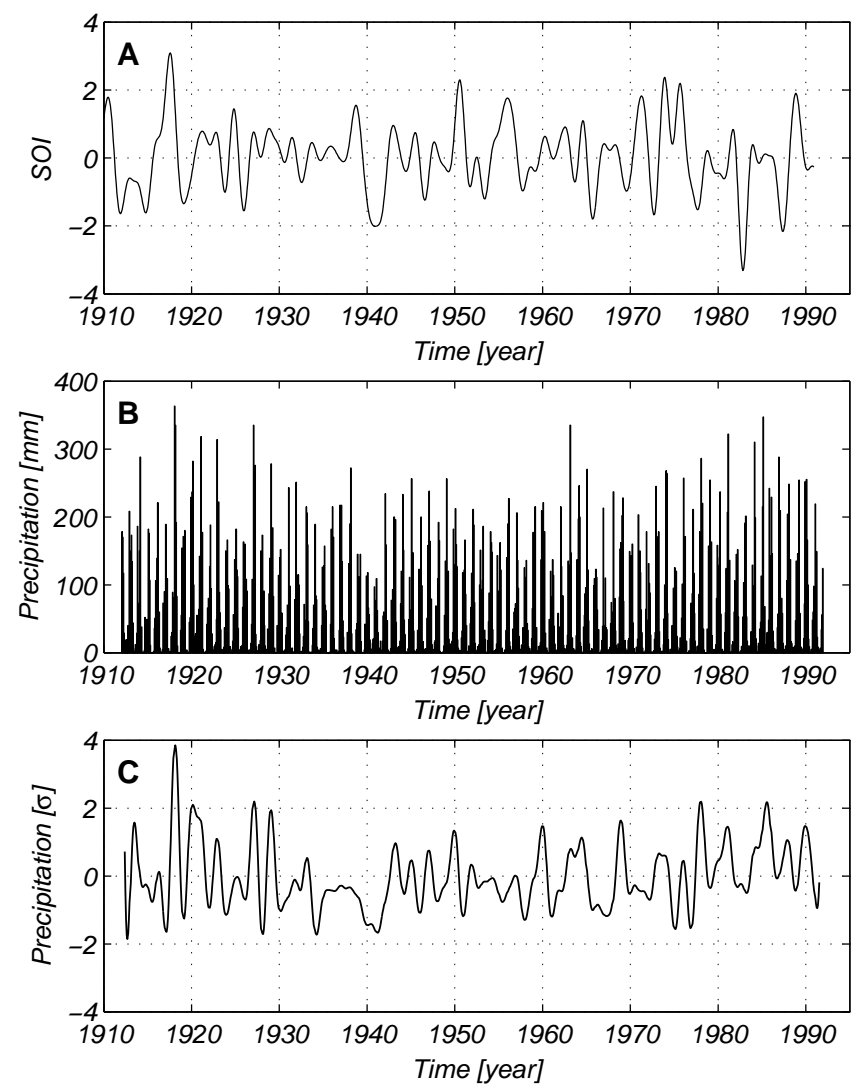

Fig. 3 Smoothed and $\sigma$-normalized time series of the Southern Oscillation Index (A), monthly precipitation data of Salta (B) and its smoothed and $\sigma$-normalized time series (C). SOI based on COADS data from the NOAA Live Access Server (http://ferret.wrc.noaa.gov). 
The CRP analysis of the present-day ENSO and precipitation data reveals characteristic patterns that can now be traced in palaeo-precipitation data. The palaeo-precipitation variability is inferred from varved lake sediments sampled at the location El Paso (EP; $26.0^{\circ} \mathrm{S}, 65.8^{\circ} \mathrm{W}$ ) in the Santa Maria Basin in NW Argentina (Figs. 10 and 4). These sediments were deposited in a landslide dammed lake $30,000{ }^{14} \mathrm{C}$ years ago (Trauth and Strecker 1999; Hermanns and Strecker 1999). Because of the internal structure of the deposits with intra-varved changing of diatom species and the cyclic recurrence of paired diatomite and clastic layers, these laminations are varves (Trauth and Strecker 1999). The annual cycle with wet summers and dry winters caused significant changes in the lake sedimentation. During the rainy season mainly ocher coloured silty sediments were deposited; during the subsequent dry season a thin white layer consisting of the skeletons of silica algae (diatoms) was deposited. Due to its white colour, the diatomaceous layers can be used to identify single years in these sediments. Recurring intense red colouration of the silty part of the annual layers is sourced from reworked older sediments which are eroded and deposited only during extreme rainfall events. Therefore, the intensity of red colour in the varved deposits can be interpreted as a proxy for precipitation variation at El Paso site (Trauth and Strecker 1999: Trauth et al. 2000). The more intense the red colour the higher was the precipitation during the rainy season.

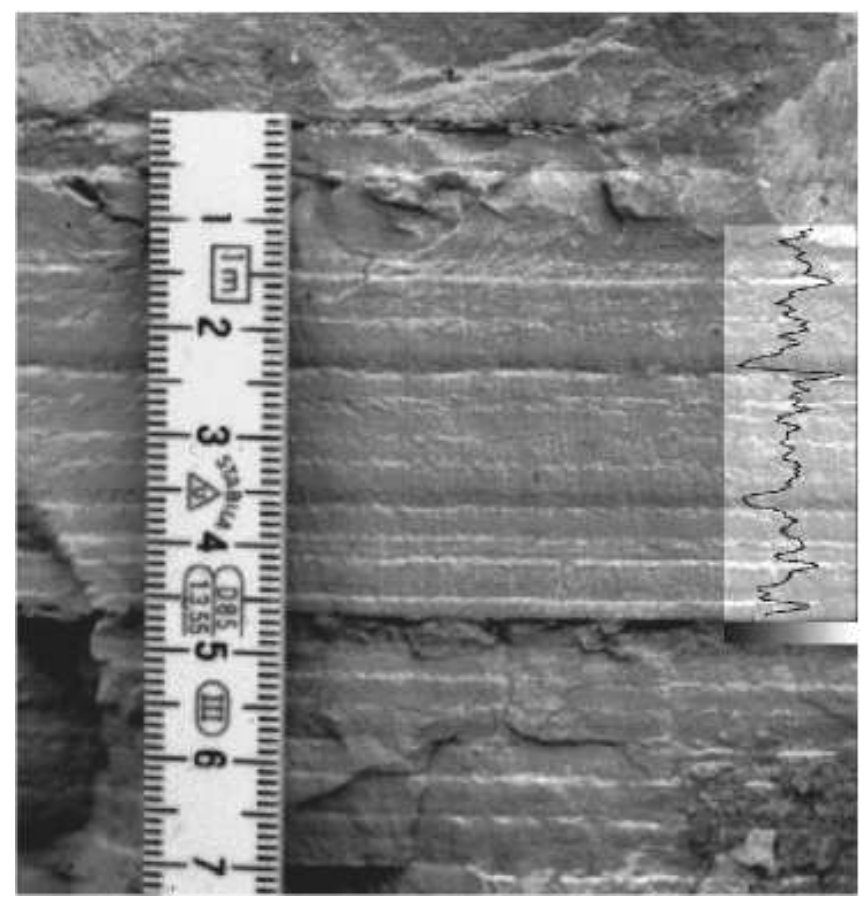

Fig. 4 Detail of varved lake sediments from the El Paso site in the Santa Maria Basin with cyclic occurrence of dark red colourations recording more precipitation and sediment flux with ENSO-like periodicities (Trauth and Strecker 1999). The overlayed curve shows a representative red colour intensity transect of the deposits.
The colour intensity of a section of the sediments profile with a length of 160 varves was gained by scanning high quality photographs. After digital pre-processing, a time series of red intensity values on a length scale was obtained. We transform these data to a time scale assuming an annual recurrence of the diatomaceous layers. Within single varves 12 subannual data points are computed by logarithmic interpolation of the data taking into account the exponential decrease of the sedimentation rate during the annual cycle (Fig. 5. The power spectrum estimate of the red colour intensity reveals significant peaks within the ENSO frequency band of 2 to 4 years, suggesting an ENSO-like influence (Trauth et al. 2000). Because of the nonstationarity of these data (the sedimentation process in a lake is not stationary, resulting in nonstationary proxy parameters for the in-lake processes; mean of the first half of the time series is 0.30 , of the second half is -0.32 ; standard deviation of the first half of the time series is 1.13 , of the second half is 0.71 ), linear correlation analysis is unsuitable. Therefore, we apply the CRP analysis to these data.
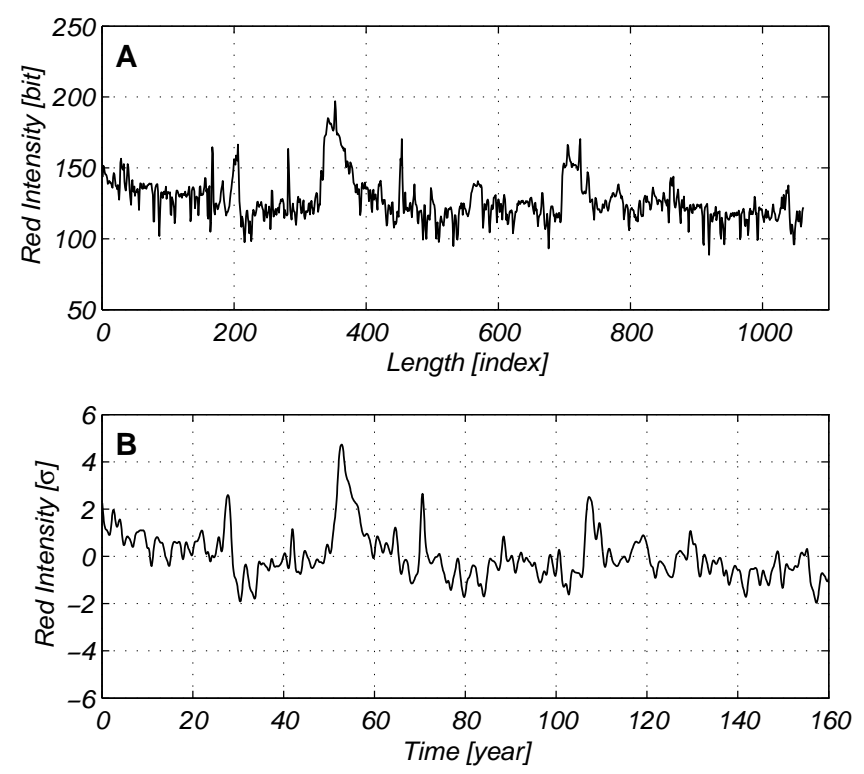

Fig. 5 Red intensity values of the lake sediments of site EP160 on (A) a length scale and on (B) a time scale and after smoothing and normalization; the unit of raw data is one bit, the unit of transformed and smoothed data is the standard deviation $\sigma$.

\section{Results of Nonlinear Data Analysis}

First, all time series are normalized and low-pass filtered using a 7th-order Butterworth filter with a cutoff frequency of $1 / 18$ month $^{-1}$ in order to remove the predominant annual cycle from the data (Figs. 3 $\mathrm{C}$ and 5. Butterworth filters are from the infinite-duration impulse response type (IIR filters) and have a monotonically decreasing response with respect to frequency (Elliott 1987). 

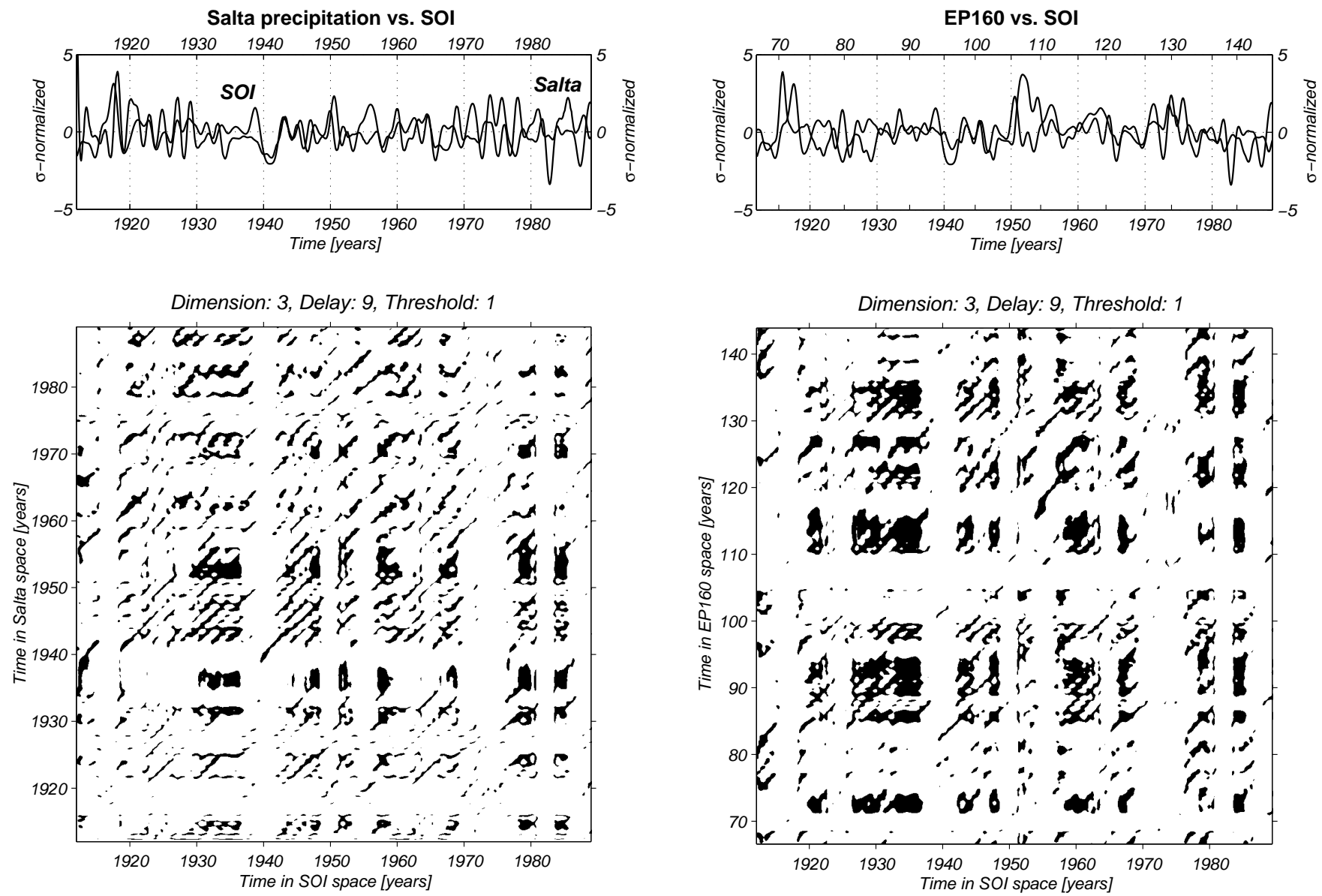

Fig. 6 Cross recurrence plot of SOI vs. precipitation data from the city of Salta (SAL). The $x$-axis shows the time along the phase space trajectory of the SOI and the $y$-axis that of SAL. Black points represent the occurrence of similar states in both processes. Diagonal lines correspond with epochs of similar dynamics in both processes. The amount and length of these lines can be used as measures of the similarity of both processes.

Next, the filtered rainfall data and the Southern Oscillation Index (SOI) are embedded into a phase space using $m=3$ and $\tau=9$. The method of nonlinear time series analysis using delay time embedding relies on a choice of good delay time and the embedding dimension. Proper values for these parameters are determined using the methods of false nearest neighbours and mutual information Kantz and Schreiber 1997). The quantitative analysis of cross recurrence plots is then applied to pairs of time series, local precipitation records and the Southern Oscillation Index (SOI). The CRPs are computed using a fixed amount of nearest neighbours with $\varepsilon=$ $15 \%$. Since the statistics of CRPs are sensitive to changes in the cutoff distance, we have run sensitivity tests in order to find the optimum value of $\varepsilon$. The value of $15 \%$ appears to be the best choice receiving robust and precise results.

The CRPs of all pairs of time series show similar features. The significant similarities between CRPs obtained from modern (Fig. 6) and palaeo-precipitation data (Fig. 7 ) indicate that the red colour intensity records from the varved lake sediment do reflect rainfall in NW Argentina. First we dis-

cuss the CRP of Salta precipitation (data series SAL) vs. the Southern Oscillation Index (SOI) and the CRP of red colour intensity of varves (data series EP160) vs. SOI. The $x$-axis represents time along the phase space trajectory of the SOI, whereas the $y$-axis represents the time along the phase space trajectory of SAL or EP160, respectively. The CRP of SAL vs. SOI exhibits longer diagonal lines in two to four year intervals, which matches the same frequency band obtained by the power spectral analysis (Fig. 6). This indicates that some sequences of the phase space trajectory of the SOI recur in sequences of the phase space trajectory of SAL after relocating by the time of two to four years. Vertical white bands in the CRP represent less frequent states in SOI, such as horizontal white bands suggest for SAL. The latter occurs with intervals of more than ten years. The CRP between EP160 and SOI shows similar characteristics as the CRP described above (Fig. [7). Longer diagonal lines have spacings of about two to four years. White bands occur at time scales of more than ten years. Some linkages in both CRPs are obvious by visual inspection. Next, the quantitative analysis of the CRPs is performed in order to study statistically these relations and 

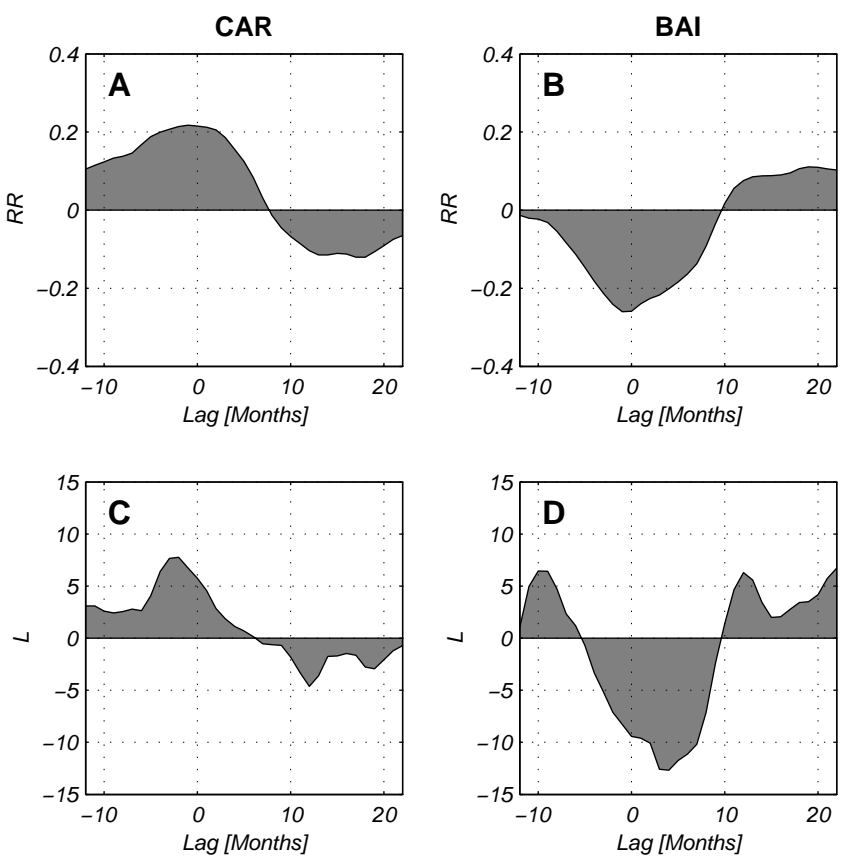

Fig. $8 R R$ and $L$ measures of the cross recurrence plots between SOI and precipitation in Caracas (A, C) and Buenos Aires (B, D) with a well-established and clear ENSO influence. Extreme values reveal high similarity between the dynamics of the rainfall and the ENSO.

to allocate the predefined causality patterns to certain localities.

In order to calculate the measures of complexity $R R$ and $L$ between the rainfall data and SOI, we used a delay time in the range between -12 and +22 months, i. e. these measures are determined in a small corridor above and below the main diagonal. We are interested in the extrema and in the time lag where they occur and we get the following results for the various pairs of records. From an ensemble of 10,000 realizations of a 5th-order AR-model we calculate the $2 \sigma$-bounds of their distributions for $R R$ and $L$. The coefficients for the ARmodel are adapted to the Tucuman precipitation (we also used AR-models adapted to the rainfall data of the other stations, which revealed similar results). The order of the AR-model is determined with the Akaike's Information Criterion and a criterion, which assesses whether the residues follow white noise (Schlittgen and Streitberg 1999).

The CRP measures between CAR and SOI reveal extreme positive values and between BAI and SOI extreme negative values, which reflect the strong influence of ENSO in these areas (Fig. 8). The parameter RR of the CRPs between TUC and SOI has small negative values, which do not exceed the $2 \sigma$-bounds, and does not show preferences for a distinct lag. The parameter $L$ has also small values, but it has rather small maxima and minima at delays of $-1,4$ and 8 months. These results indicate that the precipitation in Tucuman is not strongly influenced by ENSO. If there is a weak influence, the rainfall would increase during El Niño (Fig. 19A, E). The analysis of JUY and SOI reveals clear positive values around a lag of zero and negative values after about $8-12$ months, which suggests a significant link between Jujuy rainfall and ENSO (Fig. 9 C, G). The measures for the analysis SAL vs. SOI show smaller maxima for a delay of about zero and minima after a lag of about $8-12$ months. We therefore infer a weaker linkage between Salta rainfall and ENSO (Fig. 9 B, F; the disrupted minima in the $L$ parameter at around ten months is due to the short data length and a resulting nonstationarity in the CRP). The measures for SAL and JUY exceed the $2 \sigma$ bounds.

The $30,000{ }^{14} \mathrm{C}$ year old precipitation data are not simply comparable with present-day data, because there is no information available about how to synchronize the rainfall records with modern climate indices. Therefore we seek the time window in these data showing the highest coincidence in the dynamics using maximum values for $R R$ and $L$ as the key criterion. Although the observed coincidence is not very high, it yields the time section in the palaeo-precipitation record EP160 which can be best correlated with modern data. In our palaeo-data EP160 we find such a section represented by maximum and minima values for $R R$ and $L$ for delays of about zero and ten months, similar to those found for JUY and SAL (Fig. QDD, H). The $R R$ and $L$ measures exceed also the $2 \sigma$-bounds.

To use the minima at lags around $8-12$ months for climatological interpretations is difficult and might lead to erroneous conclusions, but these characteristic patterns of positive and negative interrelations can be used to compare the present-day and palaeo-data. The positive and negative interrelations have the same time delay between 10 and 12 months in the present-day and the palaeo-data.

\section{Discussion}

We applied the method of cross recurrence plots (CRPs) to modern and palaeo-precipitation data in order to compare the magnitude and causes of rainfall variability in the NW Argentine Andes today and during the time of enhanced landsliding at around $30,000{ }^{14} \mathrm{C}$ years ago. CRPs are able to look for nonlinear interrelations between two processes. The major result from this analysis is the significant similarity between the complex dynamics of modern rainfall and the palaeoprecipitation as recorded in the red colour intensity record from the lake sediments in the location El Paso. The distances between longer diagonal lines in the CRP of both records are about two to four years, the approximate time of recurrence of extreme ENSO phases today. The first implication of this result is that the red colour intensity of the sediments is indeed a good proxy for the rainfall intensity $30,000{ }^{14} \mathrm{C}$ ago. This result is in line with the observations of Trauth et al. (2000) suggesting an enhanced erosion of red-coloured clastic sediments during heavy rainfall events today whereas precipitation usually only reaches the elevated areas with mainly greenish low-grade metamorphic rocks exposed. This effect causes predominant greenish to buff-coloured clays deposited in the former lake basin (Trauth and Strecker 1999; Trauth et al. 2000 2003). 

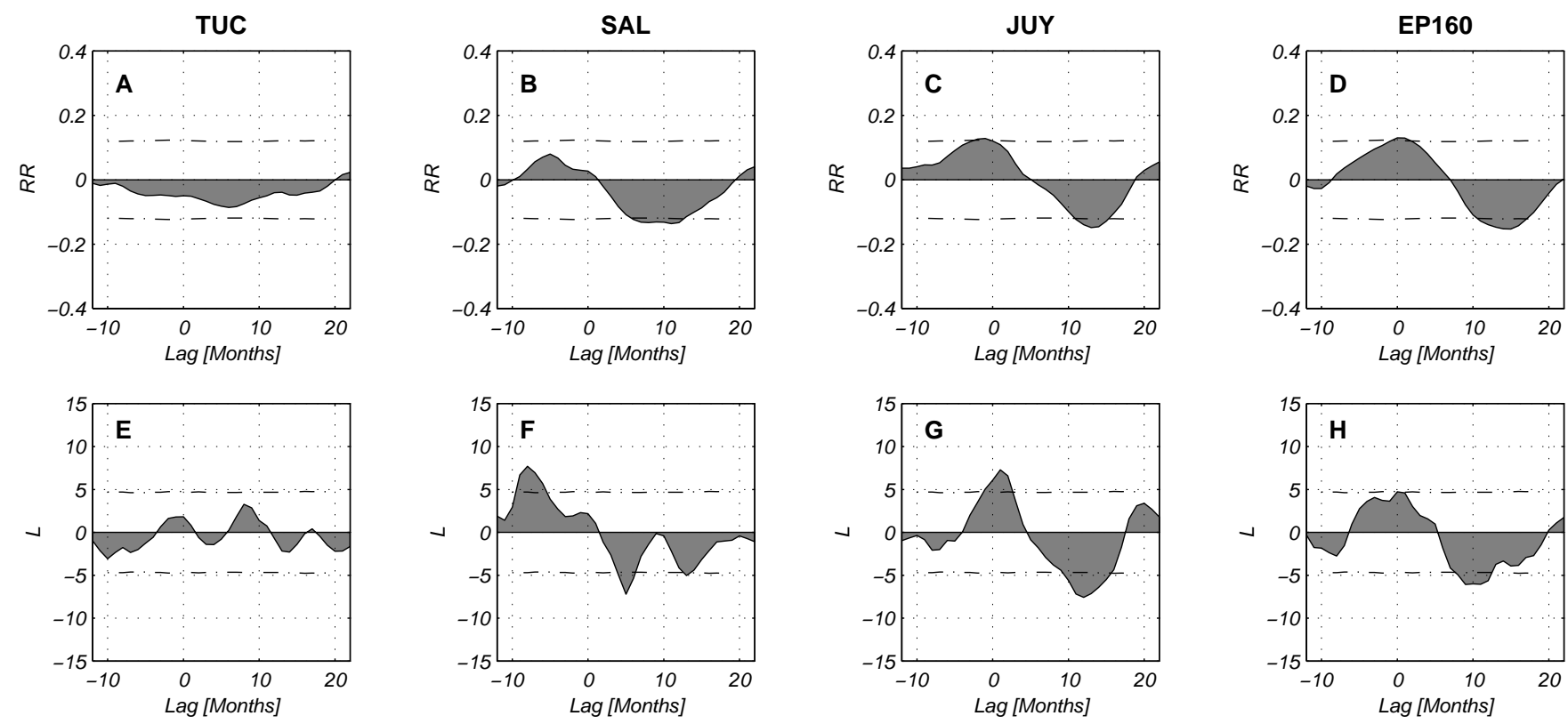

Fig. $9 R R$ and $L$ measures of the cross recurrence plots between SOI and precipitation in Tucuman (A, E), Salta (B, F), Jujuy (C, G) and palaeo-precipitation $(\mathrm{D}, \mathrm{H})$. Extreme values reveal high similarity between the dynamics of the rainfall and the ENSO. The dash-dotted lines are the empirical $2 \sigma$-bounds from the distributions of an ensemble of data based on a 5th-order AR-model.

Since our analysis of modern data reveals a strong relation between local rainfall in the northern part of the study area (Jujuy) and ENSO, we interpret this similarity as an indication of a strong ENSO-like influence in the Santa Maria Basin at around 30,000 years. In contrast, there is no significant linkage between the modern rainfall in Tucuman and ENSO. This result could indicate that ENSO does not influence precipitation in the southern part of the study area or this influence is rather diffuse or changing in time.

The CRP between the SOI and the rainfall in Jujuy and Salta reveals a positive relation without any large delay, i. e. the occurrence of an El Niño at the end of a year would cause decreased rainfall in the rainy season from November to January and the occurrence of a La Niña would cause increased rainfall during this time of the year. The opposite response after a delay of $8-12$ months is not easy to interpret, because we do not know which mechanism actually caused this linkage. The time span between the identified maxima and minima is about one year and could be explained by the fact that La Niña events often follow El Niño events. The smooth shape of the CRP measure curves are artefacts caused by low-pass filtering of the time series. The measures of CRP of Tucuman precipitation and SOI show non-significant values without any characteristic delays. The analysis of varve data reveals a significant positive relation between SOI and palaeo-precipitation at the location El Paso. Similar to the modern situation, the CRP shows a significant negative relation with SOI after a delay of about ten months. Both interrelations are rather similar to those of ENSO-JUY and ENSOSAL.

The similarities between the time series of the modern rainfall data and the palaeo-precipitation record from the lake sediments suggests that an ENSO-like oscillation was active at around $30,000{ }^{14} \mathrm{C}$ years ago (roughly corresponding to 34,000 cal. years BP), which corresponds with the results of the investigation of Coccolithophores production (Beaufort et al. 2001). A younger landslide cluster in the same region at around $5000{ }^{14} \mathrm{C}$ (corresponding to $5800 \mathrm{cal}$. years BP) was also explained by a stronger ENSO influence at that time (Trauth et al. 2000: palaeo-ENSO evidence from Keefer et al. 1998: Sandweiss et al. 2001; Haug et al. 2001). The spacing between both landslide clusters is around 28,000 years. Although two landslide clusters do not allow to infer a systematic recurrence of such events, we believe that there is some evidence that these events correspond to the periods of a strong ENSO-like variation as reported from deep-sea sediments off-shore Peru (Oberhänsli et al. 1990), in the Indo-Pacific Ocean (Beaufort et al. 2001) and New Guinea corals (Tudhope et al. 2001). These long-term ENSO records suggest a mixed precession-glacial forcing on ENSO resulting in significant 23- and 30-kyr cyclicities, which confirms model results and recently inferred relations between ENSO variability and insolation (Clement et al. 1999; Liu et al. 2000; Rittenour et al. 2000).

In the semiarid basins of the NW Argentine Andes, the ENSO-like variation could have caused significant fluctuations in local rainfall at around $30,000{ }^{14} \mathrm{C}$ years similar to the modern conditions. Together with generally higher moisture levels as indicated by lake balance modeling results, this mechanism could help to explain enhanced landsliding at around 30,000 and $5,000{ }^{14} \mathrm{C}$ years ago in the semiarid basins of the Central Andes. 


\section{Conclusions}

The quantitative analysis of cross recurrence plots has revealed similarities in the evolution of the phase space trajectory of climate indices and present-day and past rainfall. In comparison to the usually less variable climate during ice ages, our result suggests an enhanced impact of ENSO-like conditions on local climate in the Santa Maria Basin 30,000

${ }^{14} \mathrm{C}$ years ago associated with a strong inter- and intraannual variability of rainfall and an intensification of moisture transport. A more variable climate due to an enhanced ENSO-like impact could have raised the risk of landsliding in this region and could help to explain enhanced landslide activity at around $30,000{ }^{14} \mathrm{C}$ years ago.

\section{Acknowledgments}

This work is part of the Collaborative Research Center 267 Deformation Processes in the Andes and the Priority Programme Geomagnetic variations: Spatio-temporal structures, processes and impacts on the system Earth supported by the German Research Foundation. We gratefully acknowledge U. Schwarz and M. Thiel for useful conversations and discussions and U. Bahr and M. Strecker for support of this work. Further we would like to thank the NOAA-CIRES Climate Diagnostics Center for providing COADS and CMAP data.

\section{References}

Aceituno P, Montecinos A (1997) Patterns of convective cloudiness in South America during austral summer from OLR pentads. In: Preprints Fifth Int. Conf. on Southern Hemisphere Meteorology and Oceanography, Pretoria, South Africa. Amer Meteor Soc, pp 328-329

Beaufort L, de Garidel-Thoron T, Mix AC, Pisias NG (2001) ENSO-like Forcing on Oceanic Primary Production During the Late Pleistocene. Science 293: 2440-2444

Bianchi AR, Yañez CE (1992) Las precipitaciones en el noroeste Argentino. Instituto Nacional de Tecnologia Agropecuaria, Estacion Experimental Agropecuaria Salta

Bookhagen B, Haselton K, Trauth MH (2001) Hydrological modelling of a Pleistocene landslide-dammed lake in the Santa Maria Basin, NW Argentina. Palaeogeogr Palaeoclimatol Palaeoecol 169: 113-127 DOI 10.1016/S00310182(01)00221-8

Bradley RS (1999) Paleoclimatology - Reconstructing Climates of the Quaternary. Vol 64 of International Geophysics Series. Academic Press, San Diego

Clement AC, Seager R, Cane MA (1999) Orbital controls on the El Niño/Southern Oscillation and the tropical climate. Paleoceanography 14: 441-456

Dethier DP, Reneau SL (1996) Lacustrine chronology links late Pleistocene climate change and mass movement in northern New Mexico. Geology 24: 539-542

Eckmann J-P, Kamphorst SO, Ruelle D (1987) Recurrence Plots of Dynamical Systems. Europhys Lett 5: 973-977
Elliott DF (1987) Digital Signal Processing. Academic Press, San Diego.

Garreaud R, Aceituno P (2001) Interannual rainfall variability over the South American Altiplano. J Clim 14: 27792789

Garreaud R, Vuille M, Clement A (in press) The climate of the Altiplano: Observed current conditions and mechanisms of past changes. Palaeogeogr Palaeoclimatol Palaeoecol DOI 10.1016/S0031-0182(03)00269-4

Garreaud RD (1999) Multi-scale analysis of the summertime precipitation over the Central Andes. Mon Weather Rev 127: 901-921

Godfrey L, Lowenstein TK, Li J, Luoand S, Ku T-L, Alonso RN, Jordan, TE (1997) Registro Continuo del Pleistocene Tardio Basado en un Testigo de Halita del Salar de Hombre Muerto, Argentina. In: VIII Congreso Geologico Chileno. Vol 1. pp 332-336

Grosjean M, Cartajena I, Messerli B (1997) Mid-Holocene Climate and Culture Change in the Atacama Desert, Northern Chile. Quaternary Res 48: 239-246 DOI 10.1006/qres.1997.1917

Haug GH, Hughen KA, Sigman DM, Peterson LC, Röhl U (2001) Southward migration of the intertropical convergence zone through the Holocene. Science 293: 13041308

Hermanns RL, Strecker MR (1999) Structural and lithological controls on large Quaternary rock avalanches (sturzstroms) in arid northwestern Argentina. GSA Bulletin 111: 934-948

Hoffmann JAJ (1975) Climate Atlas of South America Maps of Mean Temperature and Precipitation. Unesco Cartographia, WMO

Kantz H, Schreiber T (1997) Nonlinear Time Series Analysis. University Press, Cambridge

Keefer DK, de France SD, Moseley ME, Richardson III JB, Satterlee DR, Day-Lewis AO (1998) Early Maritime Economy and El Niño Events at Quebrada Tacahuay, Peru. Science 281: 1833-1835

Kurths J, Herzel H (1987) An attractor in a solar time series. Physica D 25: 165-172 DOI 10.1016/01672789(87)90099-6

Ledru MP, Braga PIS, Soubiès F, Fournier M, Martin L, Suguio K, Turcq B (1996) The last 50,000 years in the Neotropics, Southern Brazil: evolution of vegetation and climate. Palaeogeogr Palaeoclimatol Palaeoecol 123: 239257 DOI 10.1016/0031-0182(96)00105-8

Liu Z, Kutzbach J, Wu L (2000) Modeling climatic shift of El Niño variability in the Holocene. Geophys Res Lett 27: 2265-2268

Mandelbrot BB (1982) The fractal geometry of nature. Freeman, San Francisco

Marwan N, Kurths J (2002) Nonlinear analysis of bivariate data with cross recurrence plots. Phys Lett A 302 (5-6): 299-307 DOI 10.1016/S0375-9601(02)01170-2

Marwan N, Thiel M, Nowaczyk NR (2002) Cross Recurrence Plot Based Synchronization of Time Series. Nonlinear Proc Geoph 9 (3/4): 325-331 
Nogués-Paegele J, Mo KC (1997) Alternating wet and dry conditions over South America during summer. Mon Weather Rev 125: 279-291

Oberhänsli H, Heinze P, Diester-Haass L, Wefer G (1990) Upwelling off Peru during the last 430,000 yr and its relationship to the bottom-water environment, as deduced from coarse grain-size distributions and analyses of benthic foraminifers at holes 679D, 680B, and 681B, LEG 112. In: Suess E, von Huene R (Eds.), Proceedings of the Ocean Drilling Program. Scientific Results. Vol 112. pp 369-382

Palmer TN (1999) A nonlinear dynamical perspective on climate prediction. J Clim 12: 575-591

Prohaska FJ (1976) The climate of Argentina, Paraguay and Urugay. Vol 12 of World Survey of Climatlogy. Elsevier, Amsterdam, Oxford, New York, pp 13-73

Rittenour TM, Brigham-Grette J, Mann ME (2000) El Niño Climate Teleconnections in New England During the Late Pleistocene. Science 288: 1039-1042

Ropelewski CF, Halpert MS (1987) Global and Regional Scale Precipitation Patterns Associated with the El Niño/Southern Oscillation. Mon Weather Rev 115: 1606162

Saltzman B (1990) Three basic problems of paleoclimate modeling: a personal perspective and review. Clim Dynam 5: $67-78$

Sandweiss DH, Maasch KA, Burger RL, Richardson III JB, Rollins HB, Clement A (2001) Variation in Holocene El Niño frequencies: Climate records and cultural consequences in ancient Peru. Geology 29: 603-606

Schlittgen R, Streitberg BHJ (1999) Zeitreihenanalyse. Oldenbourg, München, Wien

Strecker MR, Marret R (1999) Kinematic evolution of fault ramps and its role in development of landslides and lakes in the northwestern Argentine Andes. Geology 27: 307-310

Takens F (1981) Detecting Strange Attractors in Turbulence. Vol 898 of Lecture Notes in Mathematics. Springer, Berlin, pp 366-381

Trauth MH, Alonso RA, Haselton K, Hermanns R, Strecker MR (2000) Climate change and mass movements in the northwest Argentine Andes. Earth Planet Sc Lett 179: 243256 DOI 10.1016/S0012-821X(00)00127-8

Trauth MH, Bookhagen B, Mueller AB, Strecker MR (2003) Late Pleistocene Climate Change and Erosion in the Santa Maria basin, NW Argentina. J Sediment Res 73

Trauth MH, Strecker MR (1999) Formation of landslidedammed lakes during a wet period between 40,000 and 25,000 yr B.P. in northwestern Argentina. Palaeogeogr Palaeoclimatol Palaeoecol 153: 277-287 DOI 10.1016/S0031-0182(99)00078-4

Tudhope AW, Chilcott CP, McCulloch MT, Cook ER, Chappell J, Ellam RM, Lea DW, Lough JM, Shimmield GB (2001) Variability in the El Niño Southern Oscillation Through a Glacial-Interglacial Cycle. Science 291: 15111517

Turcq B, Pressinotti MMN, Martin L (1997) Paleohydrology and Paleoclimate of the Past 33,000 Years at the Tamaduá
River, Central Brazil. Quaternary Res 47: 284-294 DOI 10.1006/qres.1997.1880

van der Hammen T, Absy ML (1994) Amazonia during the last glacial. Palaeogeogr Palaeoclimatol Palaeoecol 109: 247-261

Vuille M (1999) Atmospheric circulation over the Bolivian Altiplano during dry and wet periods and extreme phases of the Southern Oscillation. Int J Climatol 19: 1579-1600 DOI 10.1002/(SICI)10970088(19991130)19:14<1579::AID-JOC441>3.0.CO;2-N

Vuille M, Bradley RS, Keimig F (2000) Interannual climate variability in the Central Andes and its relation to tropical Pacific and Atlantic forcing. J Geophys Res 105: 1244712460

Wolf A, Swift JB, Swinney HL, Vastano JA (1985) Determining Lyapunov Exponents from a Time Series. Physica D 16: 285-317 DOI 10.1016/0167-2789(85)90011-9

Xie P, Arkin PA (1997) Global Precipitation: A 17-year monthly analysis based on gauge observations, satellite estimates, and numerical model outputs. B Am Meteorol Soc 78: 2539-2558

Zbilut JP, Giuliani A, Webber Jr., CL (1998) Detecting deterministic signals in exceptionally noisy environments using cross-recurrence quantification. Phys Lett A 246: 122-128 DOI 10.1016/S0375-9601(98)00457-5

Zhou J, Lau K-M (1998) Does a monsoon climate exist over South America? J Climate 11: 1020-1040 